\section{SUCCESSFUL SURVIVAL OF PRIMATES RECEIVING TRANSPLANTATION WITH "DEAD," NONBEATING DONOR HEARTS}

A paucity of donor organs is the principal limitation in human heart transplantation. Prompted by our short-term studies of reanimating "dead" donor hearts in sheep, we applied the same reperfusion modifications in juvenile baboons to determine human applications in an anoxic arrest model (as occurs when non-braindead patients are extubated and allowed to die). Ten juvenile baboons (mean weight $3.6 \mathrm{~kg}$ ) were studied. Five baboons were used as donors. After being anesthetized, donors were pretreated with methylprednisolone (Solu-Medrol), 50\% dextrose, nifedipine, and prostaglandin $E_{1}$ and then paralyzed and extubated. Donors became pulseless at $7 \pm 1$ minutes and had electric arrest 9 to 18 minutes after paralysis. The five donors were left undisturbed and warm for 15, 22, 30, 30, and 31 minutes, respectively, after asystole. They were then given $250 \mathrm{ml}$ of $4^{\circ} \mathrm{C}$ Roe's crystalloid cardioplegic solution via the aortic root and the hearts were explanted into iced Euro-Collins solution. Five baboons served as recipients. After donor harvest, recipients were placed on cardiopulmonary bypass, given prostaglandin $\mathrm{E}_{1}$, and cooled to $18^{\circ} \mathrm{C}$; circulatory arrest was instituted and the recipient's heart excised. The donor heart was transplanted in an orthotopic position. Before reinstitution of bypass, $250 \mathrm{ml}$ of terminal leukocyte-depleted blood cardioplegic solution was given, then bypass was restarted and the hearts were reperfused for 60 minutes. All animals were weaned from bypass without the use of inotropic agents. All animals were extubated within 2 to 4 hours after bypass and received standard immunosuppression. Peak creatine kinase MB/total creatine kinase ratio was $0.2 \% \pm 0.2 \%$. Postoperative ejection fractions by echocardiography were $75 \%$ to $80 \%$ (mean $76 \%$ ). Animals survived 1, 9, 13, 16, and 34 days, with three deaths caused by acute rejection and one each by stroke and diarrhea/dehydration. Pathologic findings showed no areas of fibrosis or ischemic damage. We conclude that successful reanimation and engraftment can be achieved with the use of the asystolic primate heart; this work suggests that human application is realistic and could greatly expand the donor pool. (J THORAC CardiovaSC SURG 1995;109:1097-102)

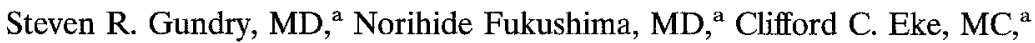
Arthur C. Hill, MD, ${ }^{a}$ Craig Zuppan, MD, ${ }^{b}$ and Leonard L. Bailey, MD, ${ }^{a}$ Loma Linda, Calif.
$T_{\text {tite }}^{\text {h }}$ he lack of available donors continues to thwart the further application of cardiac transplantation. Efforts to educate the public have failed to produce any increase in the number of transplants performed. Although mechanical replacement of failing human hearts shows promise, the use of

From the Departments of Surgery a and Surgical Pathology, Loma Linda University Medical Center, Loma Linda, Calif.

Read at the Twentieth Annual Meeting of The Western Thoracic Surgical Association, Olympic Valley, Calif., June 22-25, 1994.

Address for reprints: Steven R. Gundry, MD, Professor and Head, Division of Cardiothoracic Surgery, Department of Surgery, Loma Linda University Medical Center, 11234 Anderson St., Loma Linda, CA 92354.

Copyright (C) 1995 by Mosby-Year Book, Inc.

$0022-5223 / 95 \$ 3.00+0 \quad \mathbf{1 2 / 6 / 6 2 9 5 1}$ human heart donors clearly is preferable to any other alternative. Prompted by our success in using pediatric donor hearts that had periods of arrest and cardiopulmonary resuscitation for up to 2 hours, we began a laboratory investigation into the feasibility of "reanimating" dead pulseless donor hearts in lambs. ${ }^{1}$ Lamb hearts were successfully used for orthotopic heart transplantation after $1 / 2$ hour of cardiac electric standstill caused by either anoxia or exsanguination., ${ }^{2,3}$ Because species tolerance to ischemia varies widely, before application of cardiac reanimation in human beings could be recommended, duplication of these results in a long-term subhuman primate model appeared mandatory.

In this study we investigated the application of simple reperfusion modifications in a baboon heart 
transplant model that used "dead" hearts harvested from baboon donors who had had an anoxic death, similar to the death that occurs when patients are extubated and allowed to die a compassionate death when not fully brain dead.

\section{Material and methods}

Ten juvenile Papio baboons of 2.9 to $4.1 \mathrm{~kg}$ (mean 3.6 $\mathrm{kg}$ ) were selected as random pairs; in cases in which a size discrepancy existed, the larger of the two animals was chosen as the donor. Thus five baboons were donors and five were recipients. The donor baboons were anesthetized with ketamine hydrochloride, intubated, connected to a volume ventilator (Servo C, Siemens Corp., Lund, Sweden), and maintained with intravenous pentobarbital sodium. Eighteen-gauge intravascular catheters were placed in the femoral vessels and the arterial pressure transduced. No predonation functional studies were done. The electrocardiogram was continuously monitored. All animals were given $125 \mathrm{mg}$ of intravenous methylprednisolone and $10 \mathrm{ml}$ of intravenous $50 \%$ dextrose and started receiving intravenous prostaglandin $\mathrm{E}_{1}$ at $0.1 \mu \mathrm{g} / \mathrm{kg}$ per minute. A $5 \mathrm{mg}$ capsule of nifedipine was opened and its contents administered sublingually. Finally, $4 \mathrm{mg} / \mathrm{kg}$ of sodium heparin was administered. After 5 minutes of pretreatment, the donors were given $2 \mathrm{mg}$ of pancuronium bromide (Pavulon) and the ventilator was disconnected.

Pulselessness occurred at $7 \pm 1$ minutes after paralysis; baboons had electric arrest 9 to 18 minutes after paralysis. Animals were left undisturbed for 15, 22, 30, 30, and 31 minutes, respectively, and then a median sternotomy was done. An 18-gauge catheter was inserted into the ascending aorta, a blood sample was collected for determination of arterial blood gas values at the time of harvest, and the aorta was crossclamped. Two hundred fifty milliliters of Roe's crystalloid cardioplegic solution was instilled at $4^{\circ} \mathrm{C}$ into the aorta, with simultaneous division of both venae cavae. The heart was excised and placed for a mean of 1 hour in $4^{\circ} \mathrm{C}$ Euro-Collins solution to which $5 \mathrm{ml}$ of $50 \%$ dextrose had been added.

After donor harvest, recipient baboons were similarly anesthetized, the lungs ventilated, and maintenance with halothane inhalation instituted. A median sternotomy was done, and the pericardium was incised and fashioned into a cradle. The animals were given $4 \mathrm{mg} / \mathrm{kg}$ of sodium heparin. The ascending aorta was cannulated through a purse-string suture for arterial inflow and the right atrial appendage cannulated for venous egress to the pump oxygenator. Animals were placed on cardiopulmonary bypass support with use of an asanguineous priming solution and cooled to a rectal temperature of $20^{\circ} \mathrm{C}$.

Once cardiopulmonary bypass was begun, administration of prostaglandin $\mathrm{E}_{1}$ was started at $0.1 \mu \mathrm{g} / \mathrm{kg}$ per minute and continued until 30 minutes before gradual removal from bypass. At the same time, a $5 \mathrm{mg}$ nifedipine capsule was opened and its contents administered sublingually. After cooling was completed, the ascending aorta was crossclamped and profound hypothermic arrest was instituted. Cardiac transplantation was done in our usual fashion with the "dead" donor heart after the recipient's heart was excised. ${ }^{4}$ The venous cannula was reinserted into the donor's right atrium. Through a separate aortic purse-string suture, an 18-gauge cannula was inserted into the ascending aorta. The left atrial appendage was vented, and the baboon was given $250 \mathrm{ml}$ of leukocyte-depleted terminal blood cardioplegic solution into the aortic root. The baboon was placed back on bypass and rewarmed. The hematocrit value of the animal was concentrated up to 0.30 with an in-line ultrafilter circuit and calcium repleted during a further 50 -minute rewarming period. All five hearts returned to sinus rhythm before removal of bypass. No inotropic support was given.

After the termination of bypass and reversal of heparin with protamine sulfate, all baboons' chests were closed without drainage catheters. All animals were extubated within 4 hours of the operation and begun on oral feedings the first postoperative day. Blood was drawn before and after bypass and daily for 3 days for determination of creatine kinase (CK) and CK-MB fractions. Transthoracic echocardiograms were obtained every other day. Cyclosporine was given orally at 30 to $50 \mathrm{mg} / \mathrm{kg}$ daily, azathioprine was administered orally at $3 \mathrm{mg} / \mathrm{kg}$ daily, and $125 \mathrm{mg}$ methyl prednisolone (Solu-Medrol) was administered intravenously on the first postoperative day. Rejection episodes were treated with intravenous steroid boluses. When death occurred, autopsies were done to determine the cause of death and hearts were examined microscopically for evidence of ischemic damage and rejection.

\section{Results}

Donor hearts were harvested $15,22,30,30$, and 31 minutes after electric cardiac arrest. All hearts regained sinus rhythm and all hearts were weaned from cardiopulmonary bypass without inotropic support. All animals were extubated from 2 to 4 hours after operation. Transthoracic echocardiograms demonstrated ejection fractions from $75 \%$ to $80 \%$ (mean $76 \%$ ). The mean peak CK-MB/total CK ratio was $0.2 \pm 0.2$, with no heart eluting a large amount of myocardial CK, thus confirming the lack of significant ischemic damage.

Animals survived 1,9,13,16, and 34 days, with the death on day 1 caused by a stroke and the death on day 9 by dehydration. All other deaths were due to rejection. Autopsy on explanted hearts demonstrated minimal to no ischemic damage (Figs. 1 and 2 ), whereas rejecting hearts showed typical changes of grade 3 to 4 rejection.

All animals received humane care in compliance with the "Principles of Laboratory Animal Care" formulated by the National Society for Medical Research and the "Guide for the Care and Use of Laboratory Animals" prepared by the Institute of Laboratory Animal Resources and published by the National Institutes of Health (NIH Publication No. 86-23, revised 1985). 


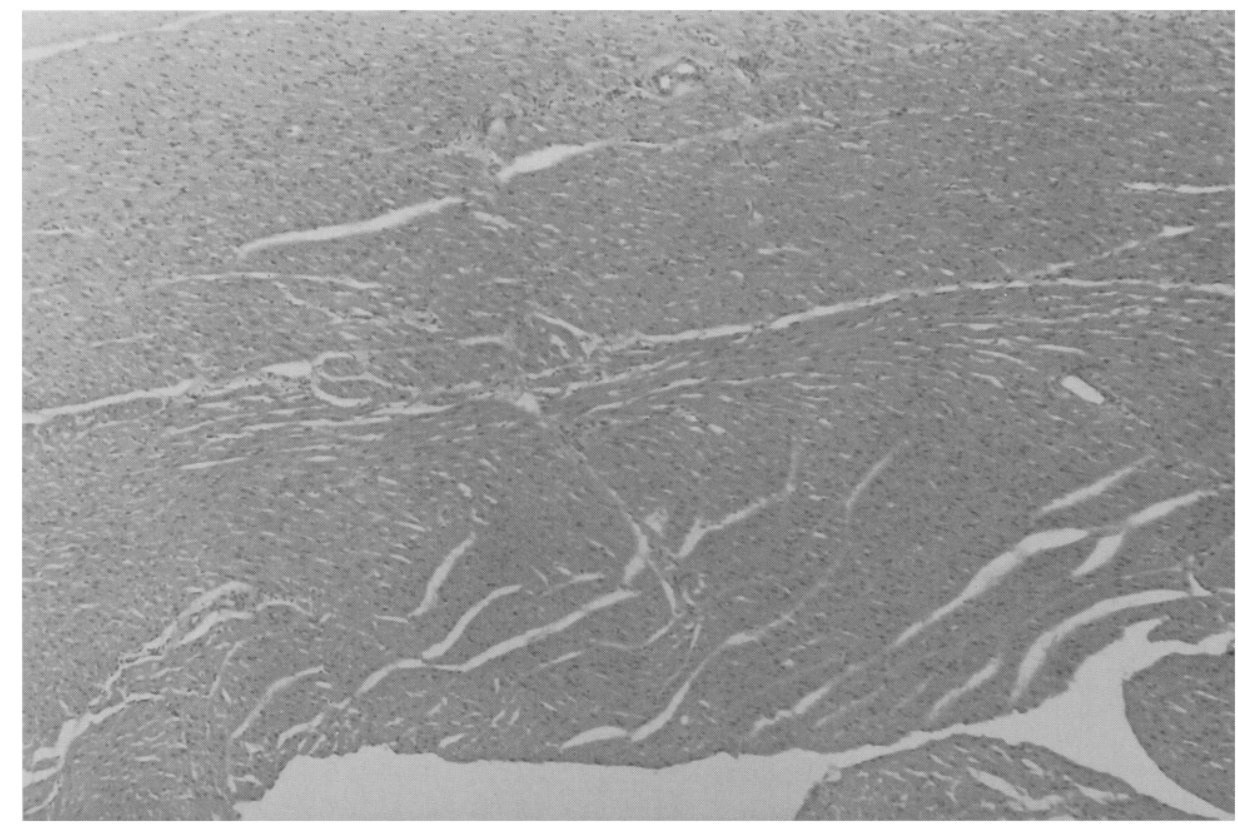

Fig. 1. Photomicrograph of transplanted "dead" heart 9 days after operation showing no ischemic changes and normal myofibrillar architecture.

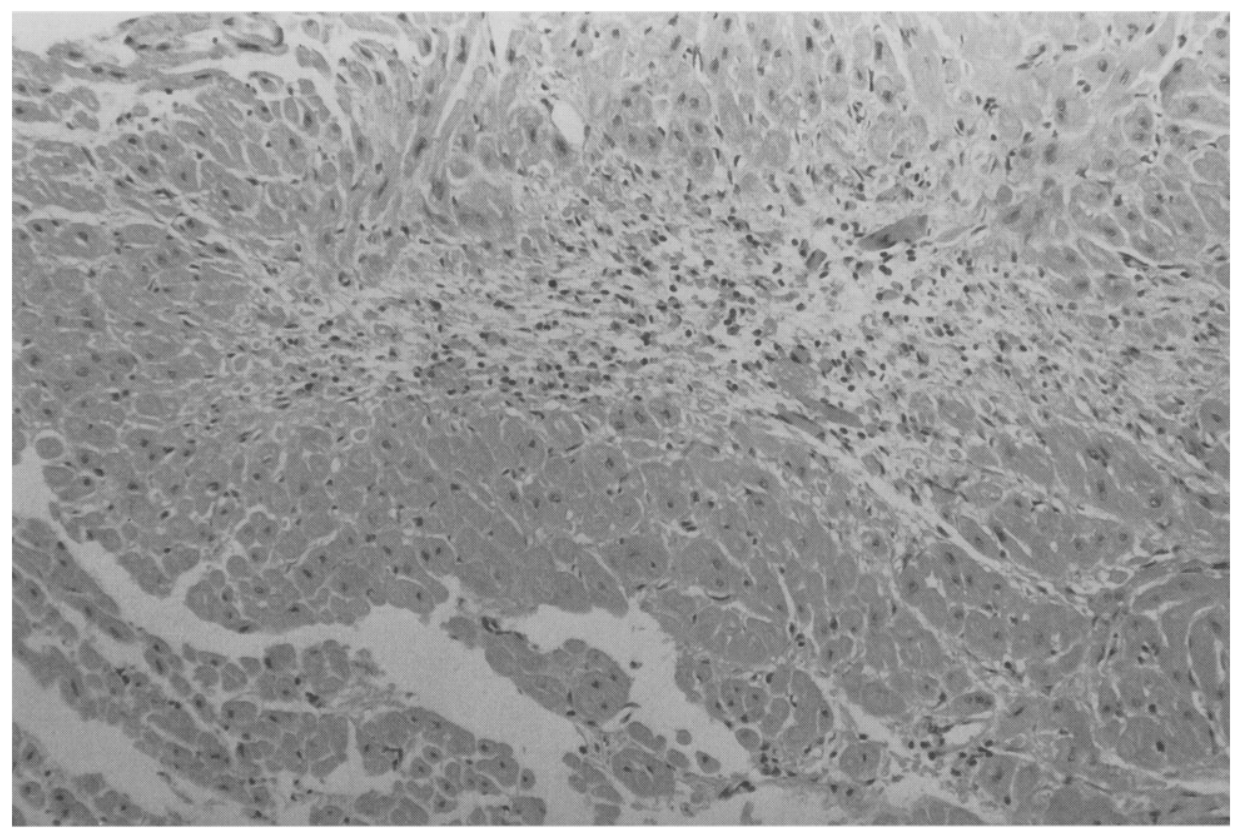

Fig. 2. Photomicrograph of transplanted "dead" heart showing minimal cellular loss perivascularly compatible with rejection or ischemic injury.

\section{Discussion}

It has been assumed that anoxically arrested hearts would be poor donors for cardiac transplantation, in that the energy stores of the heart would be severely depleted and that on reperfusion, con- traction band necrosis would invariably occur. ${ }^{5} \mathrm{CoO}-$ per ${ }^{6}$ and Lundsgaard-Hansen and associates, ${ }^{7}$ working independently, had poor results with such an animal model. However, since 1985 our clinical success with the use of infant and pediatric donor 
hearts that had been successfully resuscitated after arrest times of up to 1 hour prompted us to study how reperfusion modifications might enable "dead" hearts to be reanimated and used immediately as donor organs. ${ }^{1,8,9}$

Short-term experiments in lambs with both anoxic and exsanguination models confirmed that reperfusion modifications, with or without donor pretreatment, could reliably and consistently produce "normal" donor hearts even after 30 minutes of warm ischemia. Pretreatment of the recipient with sublingual nifedipine; prostaglandin $\mathrm{E}_{1}$ infusion; and reperfusion with a low hematocrit value (3\% to $5 \%$ ), low ionized calcium ( 0.3 to $0.5 \mathrm{mg} / \mathrm{dl}$ ), low pressure (mean arterial pressure $20 \mathrm{~mm} \mathrm{Hg}$ ), and low flow $\left(25 \mathrm{ml} / \mathrm{m}^{2}\right)$ blood reperfusate was successful in producing short-term successful orthotopic transplantation and reanimation of these "dead" hearts. ${ }^{2,3}$ However, because of species differences and the lack of long-term results, direct applicability to human beings could not be assured.

In this experiment, as in the anoxic lamb model, donors were pretreated with steroids, prostaglandin, nifedipine, and dextrose, and recipients received the same reperfusion modifications as noted for the lamb model. Additionally, a leukocyte-depleting filter was added to the terminal blood cardioplegic solution, in large part because of the success of this intervention in hearts preserved for greater than 24 hours. ${ }^{10}$

The lack of a significant reperfusion injury or permanent ischemic damage is attested to by the lack of CK-MB band elaboration, the lack of acute or chronic fibrotic/ischemic changes in the myocardium on postmortem examination, and the normal ejection fractions. These findings echo those seen in our patient population, in which neither short- nor long-term changes of ischemic damage have been seen in transplanted but previously arrested hearts. ${ }^{1,8,9}$ Although long-term survival in our series was not achieved, with three animals dying as a result of rejection 2 to 5 weeks after operation, we did not use high cyclosporine levels (range 180 to $266 \mathrm{mg} / \mathrm{dl}$ by monoclonal antibody) or FK 506, a drug that we have previously shown produces superb long-term survival in baboons, even those receiving transplant with xenografts. ${ }^{11}$ Because we have not seen accelerated rejection in hearts with long ischemic times, or in previously resuscitated hearts, 9,12 we doubt that the deaths caused by rejection in this laboratory series can be attributed to ischemic injury.
In conclusion, Baboon hearts recovered 15 to 31 minutes after cardiac standstill caused by anoxia can be transplanted, reperfused, and reanimated without difficulty with the use of clinically applicable methods. These data suggest that use of these techniques in human beings is feasible. If applied, the use of donors with nonbeating hearts could be extended to cardiac transplantation, thus greatly expanding the donor pool.

\section{REFERENCES}

1. Kawauchi M, Gundry SR, Alonso de Begona J, Razzouk AJ, Bailey LL. Utilization of pediatric donors salvaged by cardiopulmonary resuscitation. $J$ Heart Lung Transplant 1993;12:185-8.

2. Gundry SR, Alonso de Begona J, Kawauchi M, Liu H, Razzouk AJ, Bailey LL. Transplantation and reanimation of hearts removed from donors 30 minutes after warm, asystolic "death." Arch Surg 1993;128: 989-93.

3. Gundry SR, Alonso de Begona J, Kawauchi M, Bailey LL. Successful transplantation of hearts harvested 30 minutes after death from exsanguination. Ann Thorac Surg 1992;53:772-5.

4. Bailey LL, Gundry SR. Hypoplastic left heart syndrome. Pediatr Clin North Am 1990;35:137-50.

5. Jennings RB, Ganote CE. Structural changes in myocardium during acute ischemia. Circ Res 1974; 34(Suppl):156-72.

6. Cooper DKC. Resuscitation of the cadaver donor heart in the dog: I-haemodynamic, electrocardiographic, blood chemical and histopathological changes during and after death by asphyxia. Guys Hosp Rep 1974;123:333-45.

7. Lundsgaard-Hansen P, Schilt W, Heitmann L, Oroz $\mathrm{M}$, Buchler A, Lemeunier A. Influence of the agonal period on the postmortem metabolic state of the heart: a problem in cardiac preservation. Ann Surg 1971;174:744-54.

8. Boucek MM, Mathis CM, McCormack J, Gundry SR, Bailey LL. Sudden infant death syndrome (SIDS) and heart transplant donors: evidence against an intrinsic cardiac abnormality [Abstract]. Circulation 1990; 82(Suppl):III352.

9. Alonso de Begona J, Gundry SR, Razzouk AJ, Boucek MM, Kawauchi MK, Bailey LL. Transplantation of hearts after arrest and resuscitation: early and long-term results. J THORAC CARdIOVASC SURG 1993; 106:1196-201.

10. Fukushima N, Gundry SR, Shirakura R, Bailey LL. Successful long-term survival after 24-hour immersion preservation of transplanted infant goat hearts. Transplant Proc (In press).

11. Kawauchi M, Gundry SR, Alonso de Begona J, et al. Prolonged survival of orthotopically transplanted 
heart xenograft in infant baboons. J THORAC CARDIOVASC SURG 1993;106:779-86.

12. Alonso de Begona J, Gundry SR, Razzouk AJ, Boucek MM, Bailey LL. Lack of correlation between prolonged ischemic time and incidence of early and late rejection in pediatric cardiac transplantation. Cardiovasc Surg (In press).

\section{Discussion}

Dr. Adnan Cobanoglu (Portland, Ore.). During the past 5 years Dr. Gundry and his colleagues at Loma Linda have given excellent reports on marginal resuscitated pediatric donors and reanimated donors in juvenile lamb models, and this study is a natural extension of their prior work.

There has been a steady increase in the number of patients waiting for transplantation. As of May 1994 there were 2900 patients on the waiting list for heart transplantation in the United States. Only 1900 to 2000 transplants are done a year and the attrition rate while waiting may be as high as $40 \%$ on some of the lists. In an attempt to meet an ever-increasing demand for organs, most programs have extended the criteria for graft acceptability. The upper limit of the acceptable donor age was the first area that was liberalized. The second area has been acceptance of the so-called marginal donors. These are donors who do not fit the hemodynamic criteria for acceptance, those who have had prolonged cardiopulmonary resuscitation, or those receiving large doses of inotropic drugs or who have compromised left ventricular function.

Our experience in Portland with 250 transplants and our recent review for the Society of Thoracic Surgeons program have shown that with careful preoperative and intraoperative management of the donor heart a significant number of these marginal hearts, even those with up to 30 to 40 minutes of cardiac massage and resuscitation and those initially receiving 20 to $30 \mu \mathrm{g}$ of dopamine or the equivalent, can be salvaged and successfully used for transplantation.

Dr. Gundry's report takes this issue one step further. He has demonstrated that at least in the laboratory setting and in a subhuman primate, the juvenile baboon, successful heart transplantation is possible from not only braindead but also heart-dead donors. These are donor hearts with warm asystolic ischemia. This study is analogous to the discontinuation of ventilatory support for compassionate reasons in persons in vegetative states or in those who are hopelessly ill but are potential organ donors in whom a cardiac arrest and asystole will occur after the ventilator support is stopped.

I congratulate the authors for exploring this frontier, and I have a few questions. Studies have shown different responses to ischemia or anoxia, or both, in mature versus immature myocardium. Is your study clinically applicable to all donors or just to the younger ones, that is, neonates and young infants?

Dr. Gundry. These baboons are juveniles, that is, they are around 9 months to a year old and in a baboon lifetime this is equivalent to a teenager. Our studies at Loma Linda involving clinical donors have shown no difference in the tolerance of adult hearts and infant hearts to ischemia, so I would like to think that we could extrapo- late these findings in a teenage model to a fully adult model.

Dr. Cobanoglu. Did you evaluate the amount of myocardial injury by means other than the CK-MB fraction such as myosin light chain efflux or other biochemical parameters?

Dr. Gundry. No. We looked at myosin light chain efflux in a clinical study that Dr. Kawauchi in our laboratory did and found that the light chain efflux correlated very well to the CK-MB band and also to late myocardial fibrosis. In following the CK-MB band, plus the echocardiography and the lack of inotropic support, we are fairly comfortable that no major ischemic damage was done.

Dr. Cobanoglu. The duration of total ischemic time will be another important factor in the clinical setting. Will this method be applicable in the clinical setting where 3 or more hours of ischemia is common?

Dr. Gundry. That is an area of new investigation. We wanted to mimic a clinical setting in which a patient could be extubated in the intensive care unit even with the family present and allowed to die. Then the patient would simply be heparinized in that state and the surgical team. either in the intensive care unit or available in a room next door would explant the heart. I think it is practical to obtain these hearts in $1 / 2$ hour. It remains to be seen whether we can take someone from outside the hospital who has been dead for several hours and do the same manipulations.

Dr. Cobanoglu. When do you plan to take the next step from subhuman primates to human patients? Do you plan to use these reanimated hearts in high-risk recipients or on all comers, including status II patients?

Dr. Gundry. We are studying that question with our institutional review board right now. There is an ethical question and also a legal question as to the definition of death. If the definition of death is the irreversible cessation of heartbeat (which is the common definition of death in most states), does that apply to irreversible cessation of heartbeat in that particular person or does it apply to when that heart is removed, implanted in someone else, and then started again? Is that the same thing? Our legal team has advised us that the potential exists that we could be charged with murder by doing this particular procedure without legislative change in the law of defining death, so we are in limbo at this point. Obviously donors with nonbeating hearts are used in the kidney and liver fields, but again surgeons are not required to use that heart, which still remains dead in that patient.

Dr. Cobanoglu. Other than the murder charge, I think there is somewhat of an ethical decision here, because the donor heart is really dead when you accept it. How will you inform the patient? Will you tell him or her that you have a "good dead heart" available?

Dr. Gundry. I think many of our patients who are in extremis would be more than happy to take a dead heart from somebody else, particularly given the evidence that these hearts are resuscitatable. We certainly use older hearts on older recipients now, something that was unthinkable several years ago, and I can assure you that my older recipients are perfectly happy to have an older heart as long as they are alive. I think this is just one more step in a direction that we have to go as soon as the legal 
ramifications are worked out, and I am sure they can be. The point of this paper is this is the next step and it can be done.

Dr. Dimitri Novitzky (Tampa, Fla.). This is a nice animal model, but I think clinical implementation is very unlikely. In Cape Town we induced experimental brain death in baboons and documented a massive autonomic response in which there is a significant increment of circulating and endogenous catecholamine release that induces diffuse myocardial injury. There is marked subendocardial injury, as well as scattered myocyte necrosis. These observations occur as early as 30 minutes after induction of brain death. Pretreatment with calcium blockers such as verapamil abolished the catecholamineinduced injury without observation of histologic myocyte necrosis.

I would like to ask you how the initial neurologic (sympathetic) impact observed in our animal model and human donor hearts will be prevented? In this particular experimental model, after anesthesia and calcium blocker pretreatment, anoxic brain death is induced, which therefore avoids catecholamine-induced injury.

In a clinical setting, I find it hard to believe this can be applied. The brain-dead organ donors, during the agonal period, already have been exposed to the catecholamineinduced injury. The slide you showed us had a normal histologic subendocardium similar to the experiments done by us.

Dr. Gundry. I agree with you that from some experimental studies this is true. However, in all of our labora- tory studies with this identical model we have yet to produce that subendocardial injury. I think it is secondary to the modifications of how reperfusion is done. Of course, the big fear with the use of marginal donors was that these donors had huge catecholamine storms and had marginal myocardial conditions with a very low ejection fraction by echocardiography and huge amounts of inotropic support. The fear was that these were severely damaged hearts that would not work in human subjects. In fact, as Dr. Cobanoglu has pointed out and in our study, this simply does not happen when these hearts are transplanted. When they are taken out of the deleterious milieu of the brain-dead donor and put in a normal human being, these hearts respond normally, and their inotropic support is minimal. Even patients whose donor hearts have received norepinephrine, epinephrine, and huge amounts of dopamine are weaned from cardiopulmonary bypass with minimal inotropic support in the normal milieu of a healthy brain, if you will.

Additionally, Dr. Javier Alonzo de Begona, at our institution, has looked at the amount of fibrosis in hearts recovered from children who have had as long as 1 hour of downtime before cardiopulmonary resuscitation, a study that now extends to 8 years after transplantation, and has found no difference in the amount of myocardial fibrosis or in the ejection fraction of these hearts in human beings compared with these findings in hearts from donors who have not had cardiopulmonary resuscitation and have not had downtime. I suspect that in fact these laboratory data are directly transferable to the human subject. 